\title{
Prevalence of metabolic syndrome in type 2 diabetes mellitus patients using NCEP/ATP III and IDF criteria in Nepal
}

\author{
Bhattarai $S,{ }^{I^{*}}$ Kohli SC, ${ }^{l}$ Sapkota $S^{l}$ \\ ${ }^{\prime}$ Department of Medicine, Manipal College of Medical Sciences, Pokhara, Nepal
}

*Corresponding Author:

Dr. Subash Bhattarai MBBS, MD

Lecturer, Department of Internal Medicine

Manipal Teaching Hospital, Pokhara, Nepal

Email: kiwisubash@yahoo.com

\section{Citation}

Bhattarai S, Kohli SC, Sapkota S. Prevalence of metabolic syndrome in type 2 diabetes mellitus patients using NCEP/ATP III and IDF criteria in Nepal. Nepal Journal of Medical sciences 2012;1(2):79-83.

\begin{abstract}
Background: With increasing trends towards sedentary life style, obesity, diabetes mellitus, hypertension, and dyslipidaemia, the prevalence of metabolic syndrome (MetS) is rising in our country. In view of importance of diagnosis of MetS in day to day medical practice for early institution of life style therapies to reduce the atherosclerotic cardiovascular disease risk in susceptible population like in diabetes mellitus, this study has been undertaken to study the prevalence of metabolic syndrome in Nepalese diabetes by applying National Cholesterol Education Programme/Adult Treatment panel (NCEP/ATP) III and International Diabetes Federation (IDF) criteria.
\end{abstract}

Methods: This is a hospital based cross sectional study conducted in diabetes patients aged between 25-75 years of age presenting to Manipal Teaching Hospital, Pokhara. Different components of MetS were studied in diabetes subjects and prevalence of metabolic syndrome was obtained by applying NCEP/ATP III and IDF criteria respectively. The data were collected as per preformed proforma and results analyzed by SPSS- 16 software.

Results: The prevalence of metabolic syndrome in diabetes patients as per NCEP/ATP III and IDF criteria were $71 \%$ and $82 \%$ respectively. A higher number of cases with metabolic syndrome were detected using IDF criteria as opposed to NCEP/ATP III criteria in diabetes patients. Nepalese diabetes subjects showed high prevalence of abdominal obesity followed by hypertension.

Conclusions: The results of the present study show high prevalence of Mets in Nepalese diabetes patients and more number of cases can be diagnosed by applying IDF criteria as compared to NCEP/ATP III criteria.

Keywords: Diabetes mellitus; metabolic syndrome; hypertension; dyslipidemia

\section{Background:}

Wetabolic syndrome (MetS) is an aggregate of biochemical and physical conditions that presage the development of atherosclerotic cardiovascular disease. ${ }^{1}$ The concept of constellation of metabolic abnormalities linked to insulin resistance as a key component was pioneered by Reaven at the Banting lecture of American Diabetes Association annual meeting in $1988 .{ }^{2}$ He termed constellation of these metabolic abnormalities, comprising of elevated triglycerides, fasting hyperinsulinaemia and 
elevated blood pressure as "Syndrome X" and recognized it as a multiplex risk factor for cardiovascular disease. He and subsequently others postulated that insulin resistance underlies Syndrome X. ${ }^{1}$

In the recent years, there has been increasing interest in the metabolic syndrome by the American Heart Association, the American College of Cardiology, the international atherosclerotic Society and other special groups in diabetes, insulin resistance, hypertension and cardiology worldwide, effectively removing it from province of pure diabetes.

The recognition of metabolic syndrome as a disease entity by physicians has been hindered by lack of universal criteria for its diagnosis. While stressing the importance of diagnosis of MetS, the American Heart Association and the National Heart, Lung and Blood Institute joint statement states "...recognition of the syndrome in clinical practice is encouraged for the identification of a multiple risk factor condition and to promote life style therapies that will reduce all of the metabolic risk factors simultaneously." ${ }^{3}$ Various consensus panels have issued recommendations for diagnosing MetS with overriding rationale being the recognition of a syndrome of increased risk for cardiovascular disease as opposed to a state of increased risk for type 2 diabetes mellitus. The recommendations of these panels offer similar but unique syndrome defining features. The commonly employed criteria for detection of MetS are those put forward by World Health Organisation (WHO ${ }^{4}$ in 1998, National Cholesterol Education Programme Adult Treatment panel (NCEP/ATP) 5 in 2001 and International Diabetes Federation (IDF) ${ }^{6}$ in 2005. IDF and ATP III have attempted to make the concept of metabolic syndrome "user friendly" by simplifying the clinical criteria consisting of measurement of waist circumference (WC), blood pressure (BP), fasting blood glucose (FBG), high density lipoprotein Cholesterol (HDL) and triglyceride (TG).

NCEP/ATP III requires at least three of the following: ${ }^{5}$

1. central obesity: waist circumference $\geq 102 \mathrm{~cm}$ (male), $\geq 88 \mathrm{~cm}$ (female)

2. dyslipidemia: $\mathrm{TG} \geq 1.7 \mathrm{mmol} / \mathrm{L}(150 \mathrm{mg} / \mathrm{dl})$

3. dyslipidemia: HDL-C $<40 \mathrm{mg} / \mathrm{dL}$ (male), $<50 \mathrm{mg} /$ dL (female)

4. blood pressure $\geq 130 / 85 \mathrm{mmHg}$

5. fasting plasma glucose $\geq 6.1 \mathrm{mmmol} / \mathrm{l}(110 \mathrm{mg} / \mathrm{dl})$

The IDF consensus worldwide definition of the metabolic syndrome (2005) include viz, central obesity (defined as waist circumference with ethnicity specific values)and any two of the following: ${ }^{6}$

1. Raised triglycerides: $>150 \mathrm{mg} / \mathrm{dL}(1.7 \mathrm{mmol} / \mathrm{L})$, or specific treatment

2. Reduced HDL cholesterol: $<40 \mathrm{mg} / \mathrm{dL}(1.03 \mathrm{mmol} / \mathrm{L})$ in males, $<50 \mathrm{mg} / \mathrm{dL}(1.29 \mathrm{mmol} / \mathrm{L})$ in females, or specific treatment for this lipid abnormality

3. Raised blood pressure: systolic BP $>130$ or diastolic $\mathrm{BP}>85 \mathrm{~mm} \mathrm{Hg}$, or under treatment

4. Raised fasting plasma glucose: $>100 \quad \mathrm{mg} / \mathrm{dL}$ ( $5.6 \mathrm{mmol} / \mathrm{L})$, or previously diagnosed type 2 diabetes.

Waist circumferences with ethnicity specific values in IDF are as:

1. Male $\geq 94 \mathrm{~cm}$ and female $\geq 80 \mathrm{~cm}$ for European descent

2. Male $>90 \mathrm{~cm}$ and female $>80 \mathrm{~cm}$ for South Asian (Chinese, Asian-Indian) descent

3. Male $>102 \mathrm{~cm}$ and female $>88 \mathrm{~cm}$ for American descent

Individuals with metabolic syndrome are at increased risk for CHD. ${ }^{7}$ The metabolic syndrome has been associated with atherosclerotic cardiovascular disease and several obesity-related disorders including nonalcoholic fatty liver disease with steatosis, fibrosis, cirrhosis, microalbuminuria, chronic kidney disease, sleep disordered breathing, including obstructive sleep apnoea. ${ }^{8}$ Several components of the metabolic syndrome, including hyperlipidemia, hypertension, and diabetes have been associated with an increased risk of cognitive decline and dementia. ${ }^{9}$

Various studies conducted worldwide have shown high prevalence of MetS in diabetic population. However, data regarding prevalence of MetS in diabetes patients in Nepal is lacking. Controversy exists regarding the most appropriate criteria to define Mets. In view of above, this study has been undertaken employing IDF and NCEP/ATP III criteria to study prevalence of metabolic syndrome in type 2 diabetic patients in Nepal and also to see if there is significant difference in the prevalence of Mets recognized by these two frequently used criteria.

\section{Methods:}

This is a hospital based cross-sectional study conducted from October 2009 - October 2010 at Manipal Teaching Hospital, Pokhara, Nepal. Prior clearance was obtained from Institutional Ethical Committee and written consent was taken from all the subjects included in the study.

A total of 66 diabetic patients aged between 25-75 years of age presenting to the hospital were included in the study. 
Patients with type 1 diabetes, terminally ill patients and those who failed to give consent were excluded from the study.

Relevant clinical history was taken from the patients and physical examination was done. Variables like weight, height, waist circumference, waist hip ratio and blood pressure were measured. Peripheral blood sample was taken for measuring overnight fasting blood sugar, fasting lipid profile and 2 hours post prandial sugar. Diabetic subjects with Mets were identified by applying NCEP/ATP III and IDF criteria respectively. The data were collected in a preformed proforma and results were analyzed using SPSS16 software.

\section{Results:}

A total of 66 diabetes mellitus subjects (male $=44$, female $=22$ ) presenting to the hospital were included in the study. The mean age of male diabetes subjects was 55 years (range $=25$ to 75 years). Similarly the mean age of female diabetes subjects was 56 years of age (range $=25$ to 75 years).

Prevalence of metabolic syndrome in diabetes patients according to NCEP/ATP III and IDF criteria were $71 \%$ $(47 / 66)$ and $82 \%(54 / 66)$ respectively. The difference in prevalence estimated by these criteria was statistically significant $(\mathrm{p}<0.05)$ as illustrated in Table 1.

Table 1: Prevalence of metabolic syndrome in diabetic subjects evaluated with IDF and NCEP/ATP III criteria

\begin{tabular}{ccccc}
\hline VARIABLE & $\begin{array}{c}\text { NCEP / } \\
\text { ATP III }\end{array}$ & IDF & $\begin{array}{c}\text { CHI } \\
\text { VALUE }\end{array}$ & P VALUE \\
\hline $\begin{array}{c}\text { Diabetes } \\
\text { Patients }\end{array}$ & $47(71 \%)$ & $54(82 \%)$ & 111.58 & $<0.001$ \\
\hline
\end{tabular}

Prevalence of metabolic syndrome in male diabetes according to the criteria developed by IDF and NCEP/ ATPIII was $80 \%(33 / 44)$ and $72 \%(27 / 44)$ respectively as shown in figure 1.

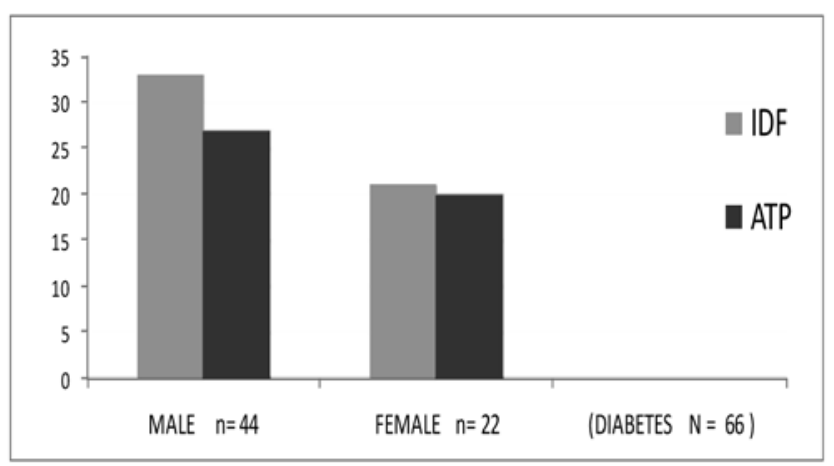

Figure 1: Number of cases of metabolic syndrome employing IDF and NCEP/ATP III criteria respectively in male and female diabetes patients.
The difference in prevalence in male subjects estimated by these criteria was statistically significant $(\mathrm{p}<0.05)$.

Prevalence of metabolic syndrome in female diabetes according to the criteria developed by IDF and NCEP/ ATPIII was 95\% (21/22) and 91\% (20/22) respectively as shown in figure1. The difference in prevalence in female subjects estimated by these criteria was statistically significant $(\mathrm{p}<0.05)$.

Among subjects with diabetes, in males, the most common component was increased waist circumference (34/44) followed by hypertension (32/44), raised Triglyceride level (27/44) and low HDL Cholesterol (25/44) as depicted in figure 2 .

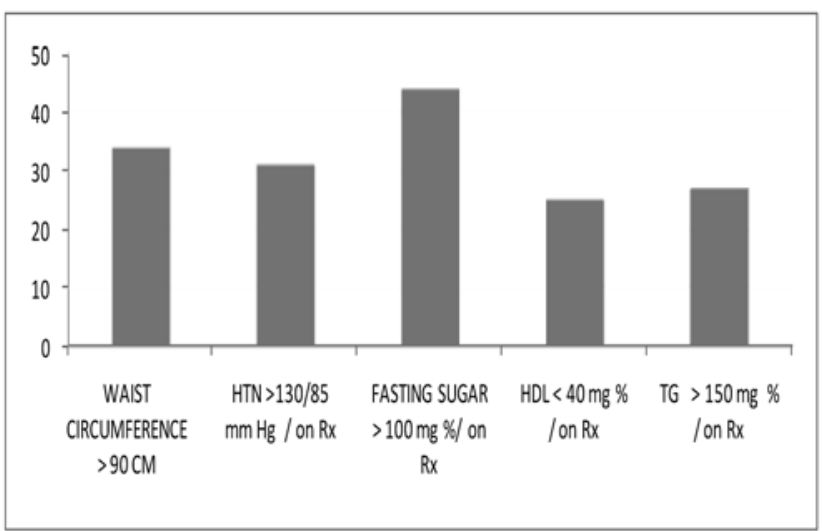

Figure 2: Occurrence of various components of metabolic syndrome in male diabetes patients

The corresponding figures in female subjects with diabetes were waist circumference $(21 / 22)$ followed by hypertension (20/22), decreased HDL cholesterol (18/22) and lastly raised Triglyceride levels (12/22) as depicted in figure 3.

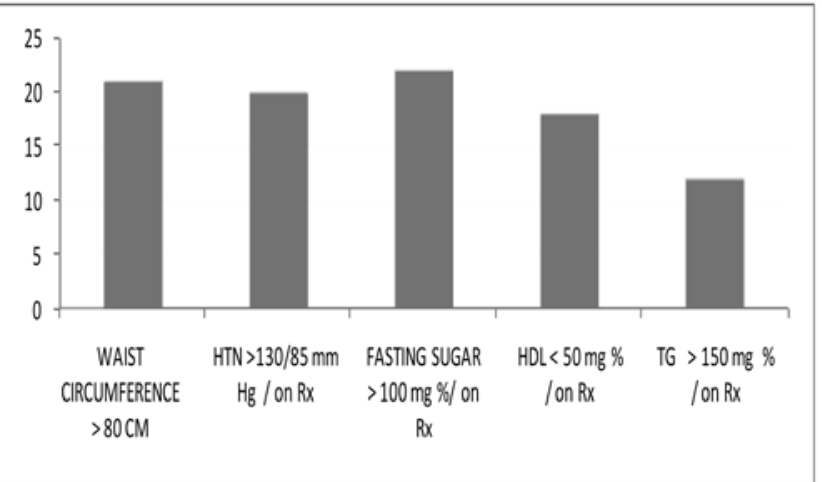

Figure 3: Occurrence of various components of metabolic syndrome in female diabetes patients

Mean BMI for male and female diabetes subjects were 25.5 $\mathrm{kg} / \mathrm{m}^{2}$ (range of 18.5 to $35.6 \mathrm{~kg} / \mathrm{m}^{2}$ ) and $26.5 \mathrm{~kg} / \mathrm{m}^{2}$ (range of 18.7 to $34.7 \mathrm{~kg} / \mathrm{m}^{2}$ ) respectively. Among risk factors of cardiovascular diseases, in diabetes, the prevalence of hypertension were $73 \%(32 / 44)$ and $91 \%(20 / 22)$ in males and females respectively. The habit of cigarette smoking or 
consumption of any form of tobacco was 75\% (33/44) and $73 \%(16 / 22)$ in males and females respectively.

\section{Discussion:}

Prevalence of metabolic syndrome in diabetes patients according to NCEP/ATP III and IDF criteria were $71 \%$ and $82 \%$ respectively in the present study. The difference in prevalence estimated by these criteria was statistically significant $(\mathrm{p}<0.05)$.

Prevalence of metabolic syndrome according to the criteria developed by NCEP/ATP III was 71\% (47/66). Prevalence in male and female were $72 \%(27 / 44)$ and $91 \%(20 / 22)$ respectively.

In a study conducted in urban areas near Mumbai, the prevalence of MetS among diabetic patients as per NCEP/ ATPIII was $77.2 \% .^{10} \mathrm{~A}$ prevalence of $79.7 \%$ was detected in a study conducted in Pakistan. ${ }^{11}$ One study reported a prevalence of $75.6 \%$ from the USA. ${ }^{12}$ The prevalence of MetS in diabetic Indian immigrants in the USA was $77 \%{ }^{13}$ A prevalence of MetS in a cross sectional survey of Italian Diabetic patients by the Metascreen writing Committee in 2006 was $69.5 \% .^{14}$

The prevalence of MetS in diabetic Nepalese population as per NCEP/ATP III in the present study is comparable to its prevalence reported in the above studies. With rapid urbanization and upgrading to sedentary life style, the prevalence of Mets can be expected to rise in Nepalese population in and around major cities.

The prevalence of MetS in diabetic population in male and female were $72 \%$ and $91 \%$ respectively in the present study as per NCEP/ATP III. The corresponding figures in a study conducted in urban areas near Mumbai, were $69.33 \%$ in males and $87.71 \%$ in females and it was reported to be statistically significant. ${ }^{10}$ The findings in the present study are similar to the findings of the above study and which also show higher prevalence of MetS in females as compared to males in this region. The higher prevalence of MetS in female diabetic population is likely to be due to higher Body Mass Index (BMI), increased waist circumference and increased waist/hip ratio prevalent in this region as compared to males, as brought out in the present study.

Prevalence of Mets in type 2 diabetes according to IDF criteria was $82 \%$. Prevalence of MetS in male and female were $80 \%$ and $95 \%$ respectively.

Nepalese diabetes subjects revealed abdominal obesity to be the main component with maximum prevalence in males and females. In diabetes male subjects, hypertension followed by raised TG levels and low HDL Cholesterol were other components while hypertension followed by low HDL Cholesterol and raised TG levels were found in diabetes female subjects. The other significant findings in the study was presence of low HDL Cholesterol levels in least number of male subjects, while raised TG levels were seen in least number of female subjects. Lower values of HDL level were found in female diabetes patients when compared with male diabetes patients.

The present study showed that, a statistically significant higher number of cases can be detected by applying IDF criteria than NCEP/ATP III criteria. The possible explanation of above seems to be use of ethnic specific waist circumference in the IDF criteria as opposed to uniformly fixed waist circumference for all ethnic groups as applied in NCEP/ATP III criteria. IDF criteria are "user friendly" and can easily be employed in day to day medical practice without any difficulty.

\section{Conclusion:}

The results of the present study show a high prevalence of metabolic syndrome in type 2 diabetes mellitus patients. More number of cases with MetS can be diagnosed by applying IDF criteria as compared to NCEP/ATP III criteria. The difference in prevalence of metabolic syndrome estimated by these criteria was statistically significant in Nepalese diabetic subjects. Nepalese diabetes mellitus subjects under study showed maximum prevalence of abdominal obesity followed by hypertension

\section{Conflict of interest: none}

\section{References:}

1. Leslie BR. Metabolic Syndrome: Historical Perspectives. Am J Med Sci 2006;330:264-8.

2. Reaven GM. Role of insulin resistance in human disease. Diabetes 1988;37:1595-607.

3. Grundy SM. Metabolic Syndrome scientific statement by the American Heart Association and the National Heart, Lung and Blood Institute. Arterioscler Thromb Vasc Biol 2005;25:2243-4.

4. World Health Organization. Definition, diagnosis and classification of diabetes mellitus and its complications: report of a WHO Consultation. Part 1: diagnosis and classification of diabetes mellitus. Geneva, Switzerland: World Health Organization; 1999. Available at http://whqlibdoc.who.int/hq/1999/WHO_NCD NCS 99.2.pdf. Accessed10 Oct, 2009

5. Expert Panel on Detection, Evaluation, and Treatment 
of High Blood Cholesterol in Adults. . Executive Summary of the Third Report of the National Cholesterol Education Program (NCEP) Expert Panel on Detection, Evaluation, and Treatment of High Blood Cholesterol in Adults (Adult Treatment Panel III). JAMA 2001;285:2486-97.

6. The International Diabetes Federation: The IDF consensus worldwide definition of metabolic syndrome 2005. Available at: http://www.idf.org/webdata/docs/ IDF_metasyndrome_definition.pdf. Accessed 10 Oct, 2009

7. Lakka HM, Laaksonen DE, Lakka TA, et al. The metabolic syndrome and total and cardiovascular disease mortality in middle-aged men. JAMA 2002;288:2709-16.

8. Sundstrom J, Riserus U, Byberg L, et al. Clinical value of the metabolic syndrome for long term prediction of total and cardiovascular mortality: prospective, population based cohort study. Br Med J 2006;332:87882.

9. Yaffe K, Kanaya A, Lindquist $\mathrm{K}$, et al. The metabolic syndrome, inflammation, and risk of cognitive decline. J Amer Med Assoc 2004;292:2237-42.
10. Surana SP, Shah DB, Gala K, et al. Prevalence of Metabolic Syndrome in an Urban Indian Diabetic Population Using the NCEP ATP III Guidelines. J Assoc Physicians India 2008;56:865-8.

11. Imam SK, Shahid SK, Hassan, et al. Frequency of the metabolic syndrome in type 2 diabetic subjects attending the diabetes clinic of a tertiary care hospital. J Pak Med Assoc 2007;57:239-42.

12. Bruno G, Merletti F, Biggeri A, et al. Metabolic syndrome as a predictor of all-cause and cardiovascular mortality in type 2 diabetes: The Casale Monferrato study. Diabetes Care 2004;27:2689-94.

13. Foucan L, Deloumeaux J, Donnet JP. Metabolic syndrome components in Indian migrants with type 2 diabetes. A matched comparative study. Diabetes Metab 2006;32:337-42.

14. Bonadonna RC, Cucinotta D, Fedele D, et al. The metabolic syndrome is a risk indicator of microvascular and macrovascular complications in diabetes: results from Metascreen, a multicenter diabetes clinic-based survey. Diabetes Care 2006;29:2701-7. 